International Journal of Current Advanced Research

ISSN: O: 2319-6475, ISSN: P: 2319 - 6505, Impact Factor: SJIF: 5.995

Available Online at www.journalijcar.org

Volume 6; Issue 3; March 2017; Page No. 2503-2506

DOI: http://dx.doi.org/10.24327/ijcar.2017.2503.0010

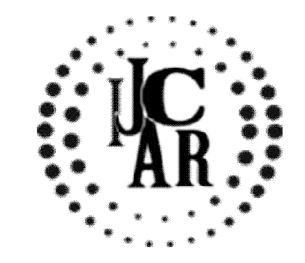

Research Article

\title{
A STUDY ON PORTAL HYPERTENSIVE COLOPATHY IN PATIENTS WITH CIRRHOSIS OF LIVER
}

\author{
Thiyagarajan G., Sabarinathan R., Ratnakar K., Pugazhendhi T., Premkumar K., Kani Shaik M., \\ Murali A., Lavkush P Tiwari
}

Institute of Medical Gastroenterology, Rajiv Gandhi Government General Hospital and

Madras Medical College, Chennai, India

A R T I C L E I N F O

Article History:

Received $5^{\text {th }}$ December, 2016

Received in revised form $19^{\text {th }}$ January, 2017

Accepted $8^{\text {th }}$ February, 2017

Published online $28^{\text {th }}$ March, 2017

Key words:

Portal hypertension, Portal hypertensive colopathy, Liver cirrhosis, Vascular ectasia.

\begin{abstract}
A B S T R A C T
Aim: In patients with cirrhosis of liver with portal hypertension, one of the important cause for lower gastrointestinal bleed is portal hypertensive colopathy. In this study, we evaluated the prevalence of colopathy in patients with cirrhosis of liver and factors associated with it. Methods: We evaluated the liver function test, ascitic fluid analysis, complete blood count, prothrombin time and child pugh class with colonoscopic findings in 25 patients over the period of 6 months. All patients underwent upper gastrointestinal endoscopy and full length colonoscopy to observe changes due to portal hypertension.

Results: We found portal hypertensive colopathy in 17 (68\%) patients. Among these patients solitary vascular ectasia in $9(36 \%)$, diffuse vascular ectasia in $10(40 \%)$, redness in $7(28 \%)$ and rectal varix in $1(4 \%)$ were noted.There was no significant relationship between Child- Turcott-Pugh class (CTP) and prevalence of portal hypertensive colopathy. Colonic mucosal changes were significantly associated with presence of esophageal varices and portal hypertensive gastropathy. Laboratory parameters such as platelet count, bilirubin level, International normalised ratio, serum albumin level and serum alanine aminotransferase (ALT) level were not related to presence of portal hypertensive colopathy. High serum ascities albumin gradient (SAAG) ascites in cirrhotic patients was associated with occurrence of portal hypertensive colopathy.

Conclusion: Portal hypertensive colopathy should be considered in the differential diagnosis of lower GI bleed in the clinical scenario of chronic liver disease. Patients with esophageal varix, portal hypertensive gastropathy, high SAAG ascites, and CTP class B and $\mathrm{C}$ should be submitted for full length colonoscopic examination.
\end{abstract}

Copyright $\bigcirc 2017$ Thiyagarajan $\boldsymbol{G}$ et al. This is an open access article distributed under the Creative Commons Attribution License, which permits unrestricted use, distribution, and reproduction in any medium, provided the original work is properly cited.

\section{INTRODUCTION}

Cirrhosis of liver is one of the major cause of portal hypertension which results in mucosal and hemodynamic changes in almost entire gastrointestinal (GI) tract. ${ }^{1}$ Esophageal varices, portal hypertensive gastropathy (PHTG) and colonic mucosal changes occurs due to portal hypertension (PHT). These complications are the most common causes of gastrointestinal haemorrhage leading to severe and life-threatening outcomes ending up in high mortality. ${ }^{2,3}$ In India, Portal hypertensive changes in lower gastrointestinal tract due to cirrhosis is less explored, except for one study done on prevalence of colonic and other changes due to portal hypertensive colopathy (PHC). ${ }^{4}$ The colorectal mucosal lesions in patients with liver cirrhosis were reported as portal hypertensive colopathy which was one of the important causes of lower gastrointestinal tract bleeding. ${ }^{5,6}$

*Corresponding author: Thiyagarajan G

Institute of Medical Gastroenterology, India City/District: Chennai
The prevalence of PHC and factors influencing it are not wellestablished in literature particularly in South Indian population. So in this study, we analysed the prevalence of PHC in patients with liver cirrhosis, factors associated with it and influence of various laboratory markers.

\section{MATERIAL AND METHODS}

Patients aged more than 18 years with cirrhosis of liver who gave consent for the study were included. Liver cirrhosis was established by physical signs, laboratory workup and features of ultrasonography of abdomen. Routine laboratory work up was performed in all patients. All were submitted for upper gastrointestinal endoscopy and colonoscopy to observe for features of portal hypertension. Along with this, physical signs and symptoms were noted. Patients with inflammatory bowel disease, hemorrhoids, fissure in ano, patients on NSAID, hemodynamically unstable, anticoagulants, undergoing radiotherapy were excluded. We prospectively enrolled 40 patients aged more than 18 years with cirrhosis of liver from January 2016 to June 2016. 15 patients were 
excluded from the study ( 8 patients didn't give the consent, 3 had hemorrhoids, 2 had fissure in ano, 2 were on anticoagulants). Finally 25 patients were included in the study. All patients underwent upper GI endoscopy under conscious sedation to evaluate the presence of esophageal varices, portal hypertensive gastropathy and gastric varices. Severity of liver disease was assessed based on Child-Pugh's classification. Ascitic fluid analysis was done and SAAG was calculated wherever necessary. All patients underwent a total colonoscopy under conscious sedation after preparation with polyethylene glycol electrolyte solution. Portal hypertensive colopathy was diagnosed by the presence of vascular ectasia, redness and blue vein. Vascular ectasia is of two types: solitary vascular ectasia and diffuse (multiple) vascular ectasia. Type, size, number and location of this vascular lesions were noted.

\section{Statistical Analyses}

Numerical data was expressed as mean \pm SD. Statistical analysis were made using chi square test for comparing categorical variables, while student unpaired ' $\mathrm{t}$ ' test was done to compare difference in mean between both groups. $P$ value less than 0.05 was considered significant.

\section{RESULTS}

In our study the median age was $51.12 \pm 8.79$ years. $23(92 \%)$ patients were male. Ascites was present in $22(88 \%)$ patients. Jaundice was seen in $17(68 \%)$. Bleeding per rectum was noted in $4(16 \%)$ subjects of which $3(75 \%)$ had PHC. The clinical characteristics of the cirrhotic patients with or without PHC are shown in Table 1. In our study, comparison of the etiology of the liver cirrhosis in patients with and without PHC revealed no statistically sigificant difference between groups (P value-0.149).

Table 1 Clinical characteristi in $10(40 \%)$, redness (Fig. 3$)$ in $7(28 \%)$ and rectal varix (Fig. $4)$ in $1(4 \%)$ patients (Table 3$)$.

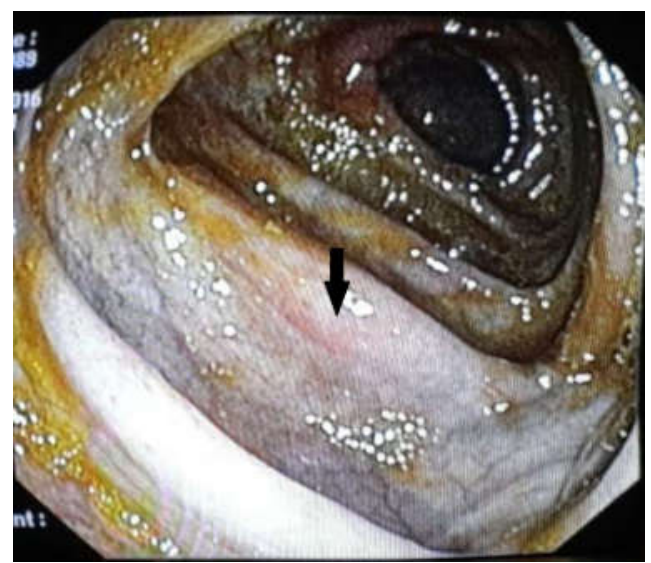

Figure 1 Colonoscpic image showing solitory vascular ectasia in transverse colon (black arrow)

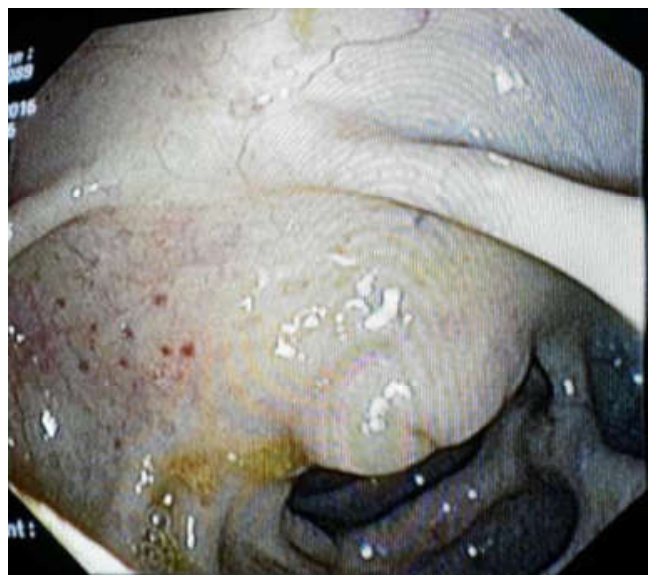

Figure 2 Colonoscpic image showing diffuse vascular ectasia in caecum

\begin{tabular}{|c|c|c|c|c|c|}
\hline & $\begin{array}{c}\text { Total cases } \\
(n=25)\end{array}$ & PHC Positive $(n=17)$ & $\begin{array}{c}\text { PHC Negative } \\
(n=8)\end{array}$ & P value & Significance \\
\hline Age (years) & $51.12 \pm 8.79$ & $50.70 \pm 9.6$ & $52.00 \pm 7.2$ & 0.739 & NS \\
\hline Sex(Male:Female) & 23:02 & $16: 07$ & 02:01 & 0.569 & NS \\
\hline Pedal edema & $10(40 \%)$ & $6(35.2 \%)$ & $4(50 \%)$ & 0.484 & NS \\
\hline Jaundice & $17(68 \%)$ & $13(76.4 \%)$ & $4(50 \%)$ & 0.186 & NS \\
\hline Bleeding per rectum & $4(16 \%)$ & $3(17.6 \%)$ & $1(12.5 \%)$ & 0.468 & NS \\
\hline Splenomegaly & $9(36 \%)$ & $8(47.0 \%)$ & $1(12.5 \%)$ & 0.093 & NS \\
\hline Hepatomegaly & $6(24 \%)$ & $4(23.5 \%)$ & $2(25.0 \%$ & 0.936 & NS \\
\hline Ascites & $22(88 \%)$ & $15(88.2 \%)$ & $7(87.5 \%)$ & 0.133 & NS \\
\hline Anemia & $16(64 \%)$ & $11(64.7 \%)$ & $5(62.5 \%)$ & 0.915 & NS \\
\hline Portal hypertension in upper GI endoscopy & $19(76 \%)$ & $15(88.2 \%)$ & $4(50.0 \%)$ & 0.037 & Significant \\
\hline $\begin{array}{c}\text { Portal hypertension in portal venous } \\
\text { doppler study }\end{array}$ & $18(72 \%)$ & $17(100 \%)$ & $1(12.5 \%)$ & 0 & Significant \\
\hline
\end{tabular}

$\mathrm{PHC}=$ Portal hypertensive colopathy; NS=Not significant

The most common etiology in both the groups was alcohol followed by cryptogenic. Of note both $\mathrm{HBV}$ and $\mathrm{HCV}$ infection related cirrhosis were present in $2(8 \%)$ patients respectively. PHC was present in all 4 cases. Features of PHT in upper GI endoscopy findings were seen in 19 patients. Among those most common finding was esophageal varix 12 (63.1\%). Esophageal varices and PHTG were related to occurrence of PHC. While other clinical findings such as pedal edema, jaundice, hepatomegaly, splenomegaly, ascites, bleeding per rectum, anemia were not significantly related to the occurance of PHC. Among 25 patients PHC was present in 17 patients $(68 \%)$, in which solitory vascular ectasia (Fig. 1) was observed in 9 (36\%), diffuse vascular ectasia (Fig. 2)
It signifies that two or more lesions were present in one person. Patients were classified into three groups based on Child-Pugh classification (Table 4). There were 3 (12\%), 13 (52\%) and 9 (36\%) patients confined to Child Pugh class A, B and $\mathrm{C}$ respectively. Out of which $\mathrm{PHC}$ was positive in $1(6 \%)$, $8(47 \%), 8(47 \%)$ of patients with Child Pugh class A, B and $\mathrm{C}$ respectively. Overall $22(88 \%)$ patients were presented with combined class B and C, among them 16 (94\%) had PHC. There existed a linear correlation between number of patients with PHC and severity of Child-Pugh class, as evidenced by increase in number of patients with $\mathrm{PHC}$ associated with the combined $\mathrm{B}$ and $\mathrm{C}$ class. But there was no statistically significant difference between the groups ( $\mathrm{P}$ value of 0.17 ). 
Table 2 Etiology of liver cirrhosis was compared with $\mathrm{PHC}$

\begin{tabular}{cccc}
\hline Etiology & $\begin{array}{c}\text { PHC } \\
\text { Present }\end{array}$ & $\begin{array}{c}\text { PHC } \\
\text { Absent }\end{array}$ & Total \\
\hline Alcohol & $12(48 \%)$ & $5(20 \%)$ & $17(68 \%)$ \\
Cryptogenic & $1(4 \%)$ & $3(12 \%)$ & $4(16 \%)$ \\
HBV infection & $2(8 \%)$ & 0 & $2(8 \%)$ \\
HCV infection & $2(8 \%)$ & 0 & $2(8 \%)$ \\
Total & $17(68 \%)$ & $8(32 \%)$ & $25(100 \%)$ \\
& $\mathrm{P}=0.149$ (Non significant) & \\
\hline
\end{tabular}

$\mathrm{HBV}=$ Hepatitis $\mathrm{B}$ virus; $\mathrm{HCV}=$ Hepatitis $\mathrm{C}$ virus $\mathrm{PHC}=$ Portal hypertensive colopathy; NS=Not significant

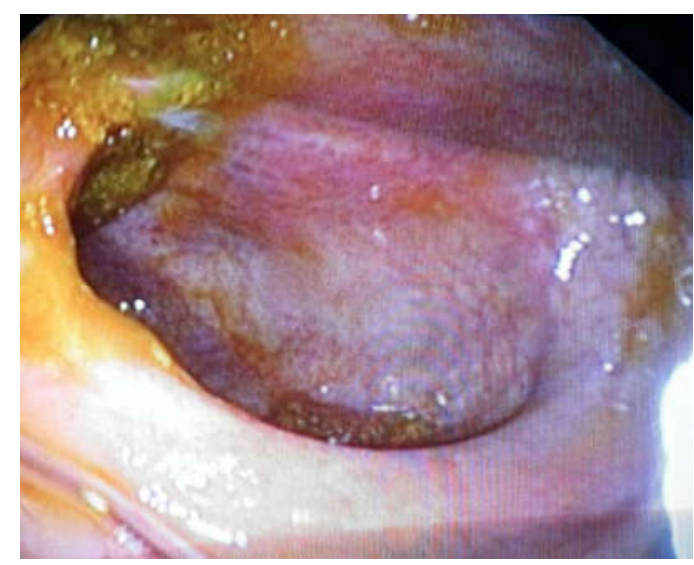

Figure 3 Colonoscpic image showing redness in sigmoid colon

Table 3 Colonoscopiclly detected number of various lesions in patients with portal hypertensive colopathy

\begin{tabular}{ccc}
\hline Site & Findings & Number of lesion \\
\hline Caecum & Diffuse vascular ectasia & $2(8 \%)$ \\
Trasnsverse colon & Solitary vascular ectasia & $1(4 \%)$ \\
Ascending colon & Redness & $1(4 \%)$ \\
Splenic flexture & Diffuse vascular ectasia & $1(4 \%)$ \\
Descending colon & Solitary vascular ectasia & $1(4 \%)$ \\
& Redness & $1(4 \%)$ \\
Sigmoid colon & Solitary vascular ectasia & $1(4 \%)$ \\
& Diffuse vascular ectasia & $4(16 \%)$ \\
& Solitary vascular ectasia & $5(20 \%)$ \\
& Diffuse vascular ectasia & $3(12 \%)$ \\
Rectum & Redness & $5(20 \%)$ \\
& Solitary vascular ectasia & $1(4 \%)$ \\
& Varix & $1(4 \%)$ \\
Total number of lesions & Solitory vascular ectasia & $9(36 \%)$, \\
& Diffuse vascular ectasia & $10(40 \%)$ \\
& Redness & $7(28 \%)$ \\
& Rectal varix & $1(4 \%)$ \\
\hline
\end{tabular}

Table 4 Child Pugh class correlation with PHC

\begin{tabular}{cccc}
\hline Child Pugh class & $\begin{array}{c}\text { Total cases } \\
(\mathbf{n = 2 5})\end{array}$ & $\begin{array}{c}\text { PHC +VE } \\
(\mathbf{n = 1 7 )}\end{array}$ & $\begin{array}{c}\text { PHC -VE } \\
(\mathbf{n = 8 )}\end{array}$ \\
\hline Class A & $3(12 \%)$ & $1(6 \%)$ & $2(25 \%)$ \\
Class B & $13(52 \%)$ & $8(47 \%)$ & $5(62.5 \%)$ \\
Class C & $9(36 \%)$ & $8(47 \%)$ & $1(12.5 \%)$ \\
Class (B + C) & $22(88 \%)$ & $16(94 \%)$ & $6(75 \%)$ \\
P value & & 0.17 & \\
Significance & & $\mathrm{NS}$ & \\
\hline
\end{tabular}

$\mathrm{PHC}=$ Portal hypertensive colopathy; NS=Not significant

The laboratory data of these patients are shown in Table 5. The parameter which significantly associated with the presence of PHC was high SAAG (P value 0.028). Other parameters like platelet count, bilirubin, ALT, AST, serum albumin were analysed with presence of PHC. Though there was difference in mean among these parameters, it was not statistically significant.

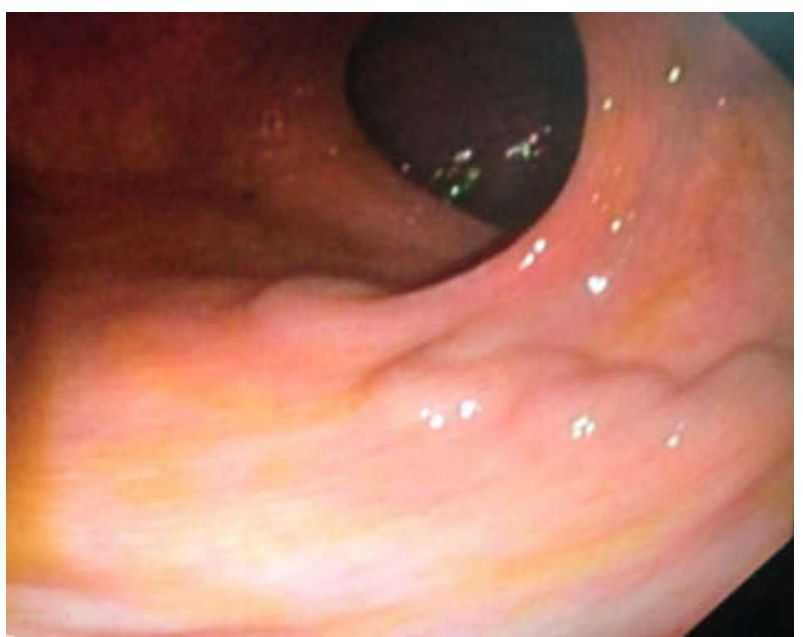

Figure 4 Colonoscpic image showing rectal varix

\section{DISCUSSION}

In our study, portal hypertensive colopathy was seen in $68 \%$ $(17 / 25)$ of the patients with cirrhosis of liver. Many previous studies showed a prevalence of $50-84 \%$ of colopathy in patients who had cirrhosis of liver and portal hypertension. ${ }^{8-10}$ Our study also had similar prevalence of colopathy. In our study, portal hypertensive colopathy was found in different locations, recto sigmoid colon was most common location with $60 \%$ of patients had lesion in that area, $20 \%$ in the descending colon, $8 \%$ in splenic flexure, $8 \%$ in the transverse colon, $4 \%$ in the ascending colon and $8 \%$ in the cecum.

Solitary vascular ectasia $5(20 \%)$ was found predominantly in the rectosigmoid colon. Diffuse vascular ectasias were found predominantly in the descending colon 4 (16\%).

Redness 5(20\%) was mostly found in sigmoid colon. In our study these findings signifies that PHC was predominantly present in the left side of the colon particularly in rectosigmoid colon.

Except for one study ${ }^{11}$ where there was significant association between child pugh class and presence of colopathy, in rest of the studies there was no significant relationship between worsening of child pugh class in correlation with colopathy. Though there was difference in number of patients in each group in class $\mathrm{B}$ and $\mathrm{C}$, it was not statistically significant similar to many previous studies. This may be due to low sample size of our study and by improving the number of patients we may get a statistically significant association.

Clinical features of liver cirrhosis like jaundice, ascites, pedal edema, bleeding PR did not have any statistically significant impact on incidence of colopathy. But there was a significant association between portal hypertension and colonic mucosal changes with a $\mathrm{P}$ value of 0.000 , which proves that cirrhotic patients with increase in portal pressure develop PHC. Contrary to one prior study ${ }^{12}$ it was observed in our study that colonic mucosal changes associated with upper GI endoscopy findings such as esophageal varices and PHTG with a statistically significant $\mathrm{P}$ value of 0.037 . The positive association was due to portal hypertension which is the common denominator for mucosal changes of whole GI tract in cirrhosis of liver. 
Table 5 Laboratory parameters correlation with PHC

\begin{tabular}{cccccc}
\hline Parameters & Total(n=25) & $\begin{array}{c}\text { PHC } \\
\text { Positive }(\mathbf{n}=\mathbf{1 7})\end{array}$ & PHC Negative (n=8) & P value & Significance \\
\hline Haemoglobin $(\mathrm{mg} / \mathrm{dL})$ & $9.11 \pm 2.08$ & $9.16 \pm 1.94$ & $9.0 \pm 2.49$ & 0.869 & $\mathrm{NS}$ \\
TWC (cells/ $\mu \mathrm{L})$ & $6972 \pm 2482$ & $7117 \pm 2962$ & $6662 \pm 951$ & 0.678 & $\mathrm{NS}$ \\
Platelet count $(\mathrm{cells} / \mu \mathrm{L})$ & $92440 \pm 55303$ & $97823 \pm 64182$ & $81000 \pm 29110$ & 0.49 & $\mathrm{NS}$ \\
Total bilirubin $(\mathrm{mg} / \mathrm{dL})$ & $4.93 \pm 5.5$ & $6.05 \pm 6.36$ & $2.55 \pm 1.57$ & 0.142 & $\mathrm{NS}$ \\
Direct bilirubin $(\mathrm{mg} / \mathrm{dL})$ & $2.67 \pm 3.22$ & $3.27 \pm 3.78$ & $1.4 \pm 0.48$ & 0.18 & $\mathrm{NS}$ \\
Indirect bilirubin $(\mathrm{mg} / \mathrm{dL})$ & $2.26 \pm 2.62$ & $2.78 \pm 2.95$ & $1.15 \pm 1.25$ & 0.151 & $\mathrm{NS}$ \\
Total protein $(\mathrm{mg} / \mathrm{dL})$ & $5.71 \pm 1.54$ & $5.78 \pm 1.68$ & $5.55 \pm 1.29$ & 0.729 & $\mathrm{NS}$ \\
Serum albumin $(\mathrm{mg} / \mathrm{dL})$ & $2.9 \pm 0.57$ & $2.78 \pm 0.56$ & $3.15 \pm 0.55$ & 0.142 & $\mathrm{NS}$ \\
ALT $(\mathrm{IU} / \mathrm{L})$ & $53.76 \pm 31.70$ & $50.76 \pm 32.87$ & $60.12 \pm 30.10$ & 0.503 & $\mathrm{NS}$ \\
AST (IU/L) & $65.80 \pm 50.26$ & $62.94 \pm 50.84$ & $71.87 \pm 51.88$ & 0.688 & $\mathrm{NS}$ \\
INR & $1.58 \pm 0.34$ & $1.58 \pm 0.35$ & $1.58 \pm 0.33$ & 0.961 & $\mathrm{NS}$ \\
Ascitic fluid-protein (mg/dL) & $1.5 \pm 1.42$ & $0.77 \pm 1.43$ & $1.84 \pm 1.32$ & 0.078 & $\mathrm{NS}$ \\
Ascitic fluid-albumin $(\mathrm{mg} / \mathrm{dL})$ & $1.26 \pm 0.87$ & $0.81 \pm 1.13$ & $1.47 \pm 0.70$ & 0.086 & $\mathrm{NS}$ \\
SAAG & $1.11 \pm 0.81$ & $1.35 \pm 0.69$ & $0.60 \pm 0.86$ & 0.028 & Significant \\
\hline
\end{tabular}

$\mathrm{PHC}=$ Portal hypertensive colopathy $\mathrm{NS}=\mathrm{Not}$ significant $\mathrm{TWC}=\mathrm{Total}$ white cell count; $\mathrm{ALT}=\mathrm{Alanine}$ aminotransferase; $\mathrm{AST}=\mathrm{Aspartate}$ aminotransferase $\mathrm{PT}=$ Prothrombin time;

$\mathrm{INR}=$ International normalised ratio

Values are expressed as mean $\pm \mathrm{SD}$

Though colonic mucosal changes $(94.1 \%)$ were more frequent in the higher class of CTP scoring system (combined class $\mathrm{B} \& \mathrm{C}$ ), where as these components individually (biochemicalbilirubin, prothrombin time, albumin \& clinical-ascites) were not correlated with occurrence of colopathy.

In our study serum ascites albumin gradient (SAAG) was one important factor related to colopathy. There was positive relationship between high SAAG to that of colonic changes due to portal hypertension with a statistically significant $\mathrm{P}$ value of 0.028 . While there was no significant relationship between presence of colopathy with ascitic fluid protein and albumin.

Among 4 patients with bleeding per rectum 1 patient had active oozing from vascular ectasia in descending colon. Patient was submitted for argon plasma coagulation and haemostasis was achieved. Other patients with features of PHT were treated with non selective beta blocker (propranalol).

Some limitations of our study are small sample size, no head to head comparison between among individuals with different CTP score and not measuring hepatic venous pressure gradient (HVPG).

\section{CONCLUSION}

Portal colopathy should be considered in the differential diagnosis of lower GI bleed in the clinical scenario of chronic liver disease. Patients with esophageal varix, PHTG, high SAAG ascites, and CTP class B and C should be submitted for full length colonoscopic examination.

\section{Acknowledgements}

The authors sincerely thank all patients for their participation in this study. We thank the nursing staff of Institute of Medical Gastroenterology of Madras Medical College and Rajiv Gandhi Government General Hospital for their support. We also thank Dr Amudhan Aravind, Dr Senthamizh selvan and Dr Breetha Sabarinathan and towards preparing this manuscript.

\section{References}

1. EASL clinical practice guidelines on the management of ascites, spontaneous bacterial peritonitis, and hepatorenal syndrome in cirrhosis. J Hepatol 2010; 53:397-417.

2. Herrera JL. Management of acute variceal bleeding. Clin Liver Dis 2014; 18:347-57.

3. Viggiano TR, Gostou CJ. Portal hypertensive intestinal vasculopathy: a review of the clinical, endoscopic, and histopathlogic features. Am J Gastroenterol1992; 87:944-954

4. Misra SP, Dwivedi M, Misra V. Prevalence and factors influencing hemorrhoids, anorectal varices, and colopathy in patients with portal hypertension. Endoscopy 1996;28:340-345

5. Kozarek RA, Botoman VA, Bredfeldt JE, Roach JM, PattersonDJ, Ball TJ. Portal colopathy: prospective study of colopathy in patients with portal hypertension. Gastroenterology 1991;101:1192-1197

6. Weinshel E, Chen W, Falkenstein DB, Kessler R, Raicht RF. Hemorrhoids or rectal varices: defining the cause of massive rectal hemorrhage in patients with portal hypertension. Gastroenterology 1986;90:744747

7. Naveau S, Bedossa P, Poynard T, Mory B, Chaput JC. Portal hypertensive colopathy: a new entity. Dig Dis Sci. 1991;36:1774-1781

8. Wang M, Desigan G, Dunn D. Endoscopic sclerotherapy for bleeding rectal varices: A case report. Am J Gastroenterol1985;80:779-780

9. Wilson SE, Stone RT, Christie JP, Panaro E. Massive lower gastrointestinal bleeding from intestinal varices. Arch Surg1979;114:1158-1161

10. Chen LS, Lin HC, Lee FY, Hou MC, Lee SD. Portal hypertensive colopathy in patients with cirrhosis. Scand J Gastroenterol 1996; 31:490-494.

11. Ito K, Shiraki K, Sakai T, Yoshimura H, Nakano T. Portal hypertensive colopathy in patients with liver cirrhosis. World J Gastroenterol 2005;11:3127-3130

12. Yamakado S, Kanazawa H, Kobayashi M. Portal hypertensive colopathy: endoscopic findings and the relation to portal pressure. Internal Medicine 1995; 34:153-157 